Document downloaded from:

http://hdl.handle.net/10251/124227

This paper must be cited as:

Pinedo-Gil, J.; Tomas-Vidal, A.; Rico, D.; Tiwaric, B.; Alvarez García, C.; Jover Cerda, M.; Sanz-Calvo, MÁ.... (2019). Effects on Lipid Oxidation and Bioactive Properties of Rainbow Trout Fillets Fed with Barley. Journal of Aquatic Food Product Technology. 28(5):495-504. https://doi.org/10.1080/10498850.2019.1604596

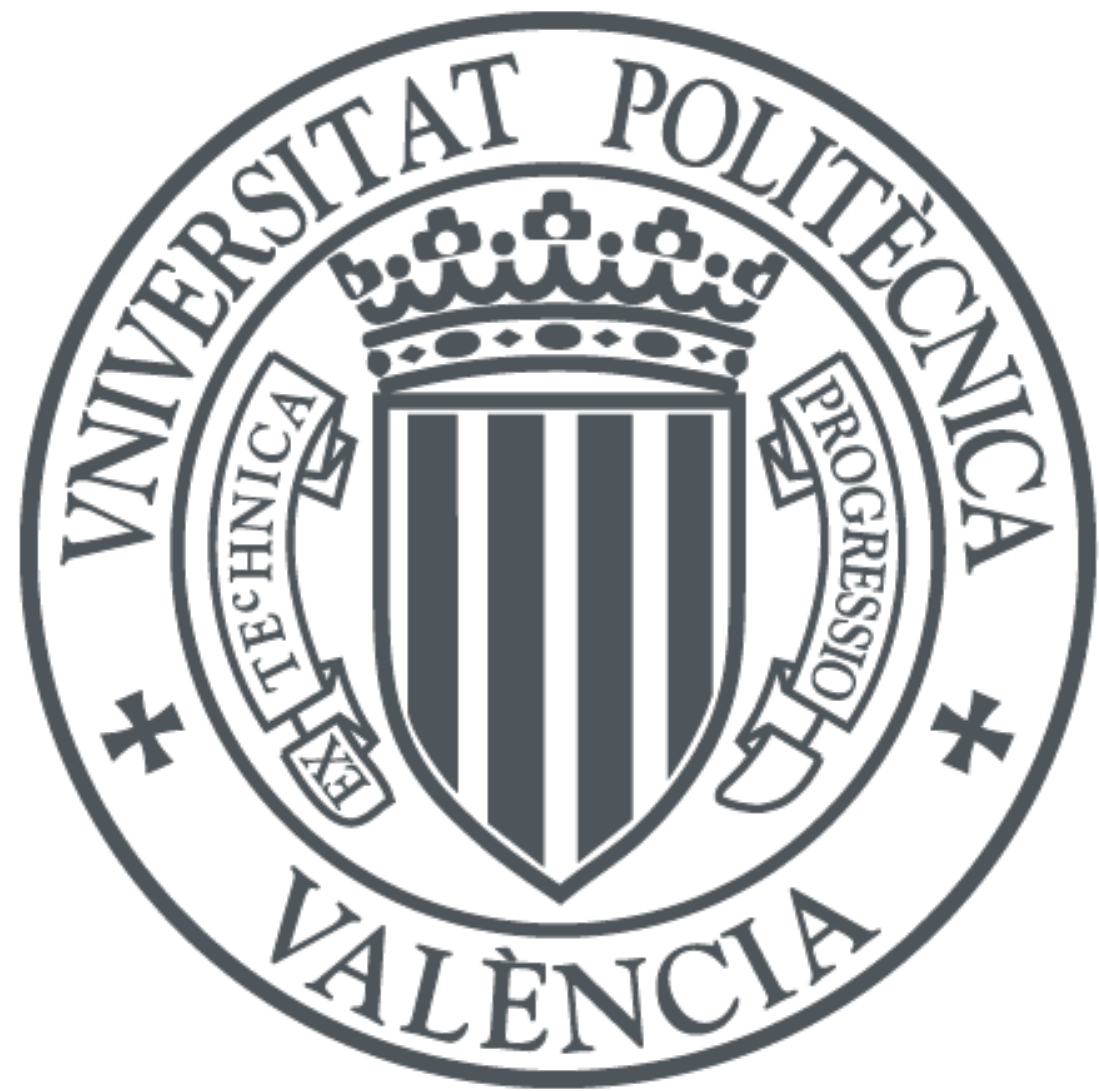

The final publication is available at

http://doi.org/10.1080/10498850.2019.1604596

Copyright Taylor \& Francis

Additional Information 


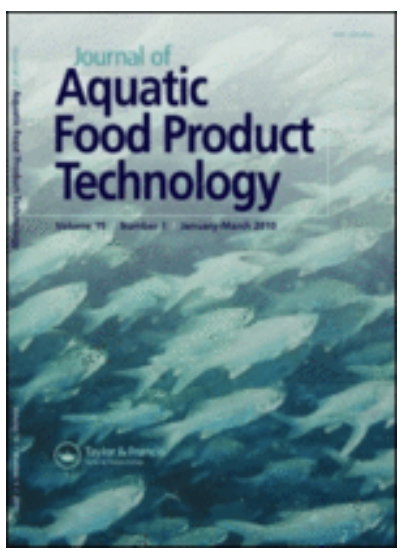

\section{EFFECTS ON LIPID OXIDATION AND BIOACTIVE PROPERTIES OF RAINBOW TROUT FILLETS FED WITH BARLEY.}

\begin{tabular}{|r|l|}
\hline Journal: & Journal of Aquatic Food Product Technology \\
\hline Manuscript ID & WAFP-2018-0102.R1 \\
\hline Manuscript Type: & Original Article \\
\hline Keywords: & Barley, Rainbow trout, Lipid oxidation, Antioxidant Activity \\
\hline \multicolumn{2}{|l}{} \\
\hline
\end{tabular}

\section{SCHOLARONE ${ }^{m}$ \\ Manuscripts}




\section{Julia Pinedo Gil \\ julia.pinedo.gil@gmail.com}

Valladolid, 2019

Dear Editor,

The authors would be grateful if you could consider the revised paper WAFT-20180102 "Effects on lipid oxidation and bioactive properties of rainbow trout fillets fed with barley”. (by J. Pinedo-Gil, A. Tomás-Vidal, D. Rico, B. Tiwari, C. Álvarez García, , M. Jover-Cerdá, M.A. Sanz-Calvo and A.B. Martín-Diana) for publication in Journal of Aquatic Food Product Technology.

We wish to thank you and the Reviewers for comments and suggestions, which greatly improved the paper. Our answers to your comments and the changes on the manuscript according to your suggestions are detailed below. Changes in the revised manuscripts are blue-typed.

\section{Comments Reviewer 1}

Reviewer 1: Growth performance characteristics data could be included in the results to see if there is any relationship between fish performance, lipid oxidation and bioactive properties of barley used as dietary supplement.

Authors: According to the reviewer suggestion fish growth performance has been included in the results section (page 8 lines 168-172 and conclusion page 12 lines 271-275) in order to study the relationship between rainbow trout performance fed with barley and their fillets lipid oxidation and bioactive properties.

Results: Page 8, lines 168-172: Growth performance was not affected by the substitution of wheat from barley. Similar results were reported by Sealey et al. (2008) who studied the effect of three barley genotypes on growth performance of rainbow trout and did not observe significant differences on final weight regardless barley concentration used.

Conclusion: Page 12, lines 271-275: It can be observed that these effects may be due to the presence of certain bioactive components in barley and not related to the fish growth. More studies should be carried out to investigate which components in barley 
Journal of Aquatic Food Product Technology Pinedo-Gil et al., 2019-Ms Ref No. WAFT-2018-0102

are the responsible to inhibit lipid oxidation and improve antioxidant properties until a concentration of $8 \%$ of barley. And reason why higher barley concentrations showed a negative effect on the fish population.

Kind regards,

The authors. 
1

2

3 Julia Pinedo-Gil ${ }^{1,2^{*}}$, Ana Tomás-Vidal ${ }^{2}$, Daniel Rico ${ }^{1}$, Brijesh Tiwari $^{3}$, Carlos Álvarez ${ }^{3}$, 4

$5{ }^{1}$ Subdirection of Research and Technology. Agro-Technological Institute of Castilla y

6 León. Consejería de Agricultura y Ganadería. Finca de Zamadueñas, Ctra. Burgos km.

7

$8 \quad{ }^{2}$ Research Group of Aquaculture and Biodiversity, Institute of Animal Science and

9 Technology, Universitat Politècnica de València, Camino de Vera, 14. 46071-Valencia, 10

12

13

14

15

16

17

18

19

20

21

22

23

24

\section{Spain.}

${ }^{3}$ Teagasc Food Research Centre. Ashtown, Dublin 15.

${ }^{*}$ Correspondig author: julia.pinedo.gil@gmail.com, atomasv@dca.upv.es

\section{EFFECTS ON LIPID OXIDATION AND BIOACTIVE PROPERTIES OF} RAINBOW TROUT FILLETS FED WITH BARLEY. Miguel Jover-Cerdá ${ }^{2}$, Miguel Ángel Sanz-Calvo ${ }^{1}$, Ana Belén Martín-Diana ${ }^{1}$ 119, 47171, Valladolid, Spain.

$\begin{array}{ll}3 & \\ 35 & 14 \\ 36 & \\ 37 & 15 \\ 38 & \\ 39 & 16 \\ 40 & \\ 41 & 17 \\ 42 & \\ 43 & \\ 44 & 18 \\ 45 & \\ 46 & 19 \\ 47 & \\ 48 & 20 \\ 49 & \\ 50 & 21 \\ 51 & \\ 52 & \\ 53 & 22 \\ 54 & \\ 55 & 23 \\ 56 & \\ 57 & 24 \\ 58 & \\ 59 & \\ 60 & \end{array}$




\section{ABSTRACT}

26 Barley concentrations ranging from $0 \%$ to $32 \%$ were incorporated into rainbow trout, 27 Oncorhynchus mykiss, diets. The effect of barley concentration on lipid peroxidation 28 and antioxidant activity were analysed on fish fillets. Results showed that the inclusion 29 of barley on rainbow trout diets had an inhibitory effect on lipid oxidation probably 30 associated with certain bioactive compounds reported on barley, which could interact 31 scavenging and reducing metabolites involved in lipid oxidation. Concentrations up to $328 \%$ of barley produced an enhanced of fish fillets showing high antioxidant activity and 33 higher levels of alpha-tocopherol.

35 Keywords: Barley, Rainbow trout, Lipid oxidation, antioxidant activity.

37 Practical Applications: Barley is a cereal not frequently used in aquaculture. The present study demonstrate that its use would be interesting due to its capacity to enhance quality, oxidative stability and the antioxidant activity of fish fillet. That makes rainbow trout fillet healthier and could promote its sale.

\section{INTRODUCTION}

Rainbow trout (Oncorhynchus mykiss) is one of the major aquaculture fish species

44 worldwide and is the second most consumed fish in Europe (FAO, 2013). During the 45 last decade, the demand of rainbow trout has increased significantly for its high nutritional value, taste and aroma (Volpe et al. 2015, Shadman et al. 2017, Erbay et al.

47 2017). Trout is an important source of high-quality proteins, polyunsaturated fatty acids 48 (PUFA's), lipid soluble vitamins and micronutrients (Alparslan et al. 2014, Volpe et al. 
49 2015, Erbay et al. 2017), although can be rapidly oxidised leading to important sensory 50 and nutritional quality losses (Pereira de Abreu et al. 2010, Yildiz et al. 2016, Erbay et 51 al. 2017).

52 Incorporation of novel ingredients to subside the aquafeed cost is essential to balance 53 product quality in order to control some negative aspects such as lipid oxidation 54 (Pratoomyot et al. 2010, Valente et al. 2015, García-Romero et al. 2014, Pinedo-Gil et al. 2017). The use of natural antioxidants or ingredients preserve and reduce oxidation during and after fish processing. Therefore, organoleptic properties can be maintained,

57 since lipid oxidation (hydroperoxide, peroxide value (PV) and their break down into 58 other secondary compounds, most of them volatile products), is involved in the 59 production of off-flavours (Razaei and Hosseini 2008).

60 Barley is an important source of $\beta$-glucans and other bioactive components such as 61 phenolic compounds, which can control oxidative processes (Sandhu and Punia 2017).

62 The use of barley on rainbow trout diets is not currently implemented at industrial scale, 63 although few studies have investigated their incorporation on diet. It was observed that 64 the incorporation of barley did not produce any negative effect on productive 65 parameters (Sealey et al. 2008, Pinedo-Gil et al. 2017), however, more studies are 66 required. For this reason, the objective of this study was the evaluation of oxidative 67 parameters and bioactive properties of rainbow trout fed at different barley 68 concentrations.

\section{2. MATERIAL AND METHODS}

\section{$70 \quad$ 2.1. Experimental design}

71 Rainbow trout were provided by a commercial trout farm (IPEASA, Fuentidueña, 72 Segovia, Spain). The average weight for each fish was $127 \pm 2.62 \mathrm{~g}$ (least-square mean 
$73 \pm$ SEM). Fish were fed with five isoproteic (40\% crude protein) and isolipidic diets

74 (18\% crude fat), which contained different barley levels $(0-31.9 \%$, named $0 \mathrm{~B}, 40 \mathrm{~B}$, 75 80B, 160B and 319B) (Pinedo-Gil et al. 2017). There were five feeding treatment 76 groups each in four replicates $(n=4)$. Fish were randomly sampled every 28 days $(0,28$, 7756 and 84 days) and skinless fish fillets were prepared for the evaluation. Three fish per 78 replicate were evaluated for the different analysis $(n=12)$. The skin was removed and 79 fillets were kept frozen until analysis. Prior to analyses, all fish were starved for $24 \mathrm{~h}$ and anesthetized with MS222®; $200 \mathrm{mg} \mathrm{L}^{-1}$. The duration of the trial was 84 days.

\subsection{Fatty acid profile (FAME)}

Fatty acid profile (FA) was determined in barley, diets and fish fillets by triplicate. Blight and Dyer (B\&D) method (Blight \& Dyer 1959) was used for lipid extraction. Lipid-containing chloroform phase was separated and after evaporated. The remaining phase was dissolved in $1 \mathrm{~mL}$ of hexane and a methylated procedure carried out by adding $100 \mu \mathrm{L}$ of $0.5 \mathrm{M}$ methanolic $\mathrm{KOH}$ and leaving the reaction for $10 \mathrm{~min}$ at room temperature (RT). The upper layer was transferred to a $2 \mathrm{~mL}$ vial. Analysis of FA methyl esters (FAME) were carried out on a gas chromatograph Agilent 7890A (Agilent Technologies, PA, California, USA) and a flame ionization detector. For the analysis the method was run on $50{ }^{\circ} \mathrm{C}$ to $200{ }^{\circ} \mathrm{C}$ during the first $7 \mathrm{~min}$ at a rate of $3{ }^{\circ} \mathrm{C} \min ^{-1}$ and held for $26 \mathrm{~min}$. Injector and detector temperature were $250{ }^{\circ} \mathrm{C}$ and $280{ }^{\circ} \mathrm{C}$, respectively. After, $1 \mu \mathrm{L}$ of the hexane extract was injected in split mode (ratio 25:1), and FAMEs were identified by comparison of retention times with those of 37 FAMEs standard mix (Supelco, Sigma-Aldrich, CO).

\subsection{Alpha-tocopherol content}


96 Tocopherol content was determined according to the AOCS official method (1992) for 97 fish fillets samples, using Agilent 1200 series HPLC equipped with a diode array detector. Two grams of the B\&D extract was evaporated and resuspended in $2 \mathrm{~mL}$ of

99 hexane with $20 \mu \mathrm{L}$ of tocopherol acetate as internal standard. An aliquot $(10 \mu \mathrm{L})$ was 100 injected and a column (250 mm x 4.6mm $5 \mu \mathrm{m})$ (Teknokroma Anlítica S.A., Barcelona, 101 Spain) was used. Elution was performed using an isocratic mixture of hexane:2102 propanol (99.6:0.4; v:v) at a flow rate of $1.3 \mathrm{~mL} \mathrm{~min}^{-1}$. Detection was set at $295 \mathrm{~nm}$ and

$103284 \mathrm{~nm}$ for tocopherol acetate. Results were expressed in $\mu \mathrm{g}$ tocopherol per gram of 104 fillet.

105 2.4. Oxidative parameters

$106 \quad$ 2.4.1 Peroxide value (PV)

107 PV was measured on the fish fillet using B\&D extract according to the International 108 IDF Standards method (1991). Results were expressed in meq of active oxygen per $\mathrm{kg}$ 109 of lipids.

\section{$110 \quad$ 2.4.2. Conjugated hydroperoxides (dienes and trienes)}

111 Conjugated hydroperoxides (fish fillet B\&D extract) were measured as described by 112 Undeland et al. (1998). Results were calculated as mmol of hydroperoxides per kg lipid.

\section{$113 \quad$ 2.5. Antioxidant markers}

\section{$114 \quad$ 2.5.1. Total Flavonoid determination (TFC)}

115 TFC was determined using the method described by Lin and Tang (2007) for barley and 116 diets. Aliquots of $0.1 \mathrm{~g}$ of sample were dissolved in $1 \mathrm{~mL}$ of $10 \%$ aluminium chloride 117 hexahydrate $\left(\mathrm{AlCl}_{3}\right), 0.1 \mathrm{~mL}$ of $1 \mathrm{M}$ potassium acetate $\left(\mathrm{CH}_{3} \mathrm{COOK}\right)$ and $2.8 \mathrm{~mL}$ of 118 deionized water. After incubation at room temperature (RT) for 40 minutes the reaction 119 was measured at $415 \mathrm{~nm}$ (Shimadzu PharmaSpec UV-1700. Milton Keynes, UK). The 
120 data were expressed as quercetin equivalent (QE) per $100 \mathrm{~g}$ of sample based on the

121 moisture content of lyophilized powder and "fresh sample".

\section{$122 \quad$ 2.5.2. Extract preparation}

123 Barley, diets and fish fillet were used for extracts preparation to measure antioxidant

124 activity. One gram of blended sample was dissolved in $10 \mathrm{~mL}$ of $90 \%$ methanol. The

125 extraction was accelerated using a ceramic homogenizer in the test tubes and stirring for $12630 \mathrm{~s}$. Following samples were centrifuged at $1.635 \mathrm{x} \mathrm{g}$ for $10 \mathrm{~min}$ at $4{ }^{\circ} \mathrm{C}$ and the 127 supernatants were collected, filtered and stored at $-80^{\circ} \mathrm{C}$. All the extracts were used for 128 the determination of total phenols and oxygen radical absorbance capacity (ORAC).

$129 \quad$ 2.5.3.Total phenols (TP)

130 TP were measured using the Folin-Ciocalteu method (Slinkard and Singleton 1977) on 131 barley, diets and fish fillets. Results were expressed as mg of gallic acid per gram of 132 dried weight (dw) sample.

133 2.5.4. Phenolic characterization using high-performance liquid chromatography 134 (HPLC)

135 Phenolic characterization was determined on barley and diets. Five gramms of sample 136 were mixed with $45 \mathrm{~mL}$ of $80 \%$ ethanol $(\mathrm{v} / \mathrm{v})$ and after it was sonicated in a water bath

137 for $1 \mathrm{~h}$. After centrifugation $\left(5000 \mathrm{x} \mathrm{g}, 20 \mathrm{~min} ., 10{ }^{\circ} \mathrm{C}\right)$, the supernatant was removed 138 and the extraction was repeated twice. Supernatants were mixed and after evaporated at $13940{ }^{\circ} \mathrm{C}$ with nitrogen until complete dryness, reconstituted in $2 \mathrm{~mL}$ of $40 \%$ acetonitrile 140 and then it was filtered through $0.45 \mu \mathrm{m}$ membrane for HPLC analysis (Bonoli et al. 141 2004, Zhao et al. 2006).

142 The phenolic compounds were separated and quantified using the method described by 143 Schieber et al. (2001) with modifications, briefly as follows. Water Alliance 2795 
144 Chromatography Separations Module (Waters Corp., Milford, USA) coupled to a 145 Waters 2996 PDA detector fixed at $280 \mathrm{~nm}$ of wavelength. Column employed was 146 Zorbax sb-c18 Agilent (4.6 x $150 \mathrm{~nm}) 5$ microns. The mobile phases consisted in $0.5 \%$ 147 acetic acid (buffer $\mathrm{A})$ and 20\% (0.5\% acetic acid):80\% acetonitrile (buffer B). Initial 148 gradient started with $5 \%$ of buffer B for 1 minute, and then was increased up to a 55\% 149 for 50 minutes; the column was cleaned for 5 minutes by pumping $95 \%$ of buffer B and 150 finally it was re-equilibrated for another 10 minutes. Calibration curves were 151 constructed using the following standards: gallic acid, chlorogenic acid, ferulic acid, p152 cumaric acids, synaptic acid, 3-coumaric acid, 4-coumaric acid, syringic acid, maleic 153 acid, transcinamic acid, vanilic acid, caffeic acid and 4-hydroxibenzoic acid at 154 concentration of $5,10,20,40$ and $80 \mu \mathrm{g} \mathrm{mL}-1$.

\section{2.5.5. Determination of the oxygen radical absorbance capacity (ORAC)}

156 The procedure was based on the method described by Ou et al. 2001. The determination 157 was measured on fish fillets. Results were expressed as $\mu \mathrm{mol}$ of Trolox Equivalent (TE) 158 per g of sample (dw).

\section{2.6. Statistical analysis}

160 Statistical analysis was performed using SAS version 9 (SAS Institute Inc., Cary, North

161 Caroline, USA) by a GLM procedure for the variance analysis (ANOVA) followed by a 162 t-Student test and considering significant differences between values with a P-value < 1630.05.

\section{3. RESULTS AND DISCUSSION}

165 Proximate composition and $\beta$-glucan in barley, experimental diets and fillets were 166 determined in Pinedo-Gil et al. 2017. It was observed that all diets were isoproteic (40\% 167 protein) and isolipidic (18\% lipid), barley contained 5.2\% $\beta$-glucan and its inclusion on 
168 experimental diets introduce this component to the diets ( 0 to $1.5 \% \beta$-glucan). Growth

169

170

171

172 final weight regardless barley concentration used. In fillet, the inclusion of barley

173 increased significantly crude fat while protein was not affected.

174

175 The replacement of wheat with barley in rainbow trout diets resulted in a marked 176 decrease of linoleic acid (C18:2 n-6), linolenic acid (C18:3 n-3) and docosahexanoic 177 acid (DHA, C22:6 n-3) in the experimental diets compared with the control (Table 1). 178 However, results showed that although the fatty acid profile change with the 179

\subsection{Fatty acid profile} concentration of barley, it had not a significant effect on fillets total SFA's, MUFA's or PUFA's (Table 2). Significant differences $(\mathrm{P}<0.05)$ were observed when individual FA's were analysed: an increase on myristic acid (C14:0) and palmitic acid (C16:1) levels on fish fed with 319B diets. The fatty acid composition was in agreement with values for fresh rainbow trout fillets as reported by other authors (Ozden 2005, Volpe et al. 2015). It is well known that the fatty acid composition of fish fillets reflects the fatty acid composition of the diet (Turchini et al. 2009, Volpe et al. 2015) but is also modified by metabolic processes (Drew et al. 2007). Trout can elongate and desaturate C18:3 n-3 into the longer chain n-3 fatty acids (Tocher et al. 2001). Probably, for this reason, although fish fed with barley showed less PUFA content these differences were not significant.

\subsection{Alpha-tocopherol content}


191 Alpha-tocopherol content was measured on fillets from fish fed at different barley 192 concentrations. Fish fed with diets 80B showed significantly higher $\alpha$-tocopherol 193 content than control and fish from the rest of experimental diets (Figure 1). Alpha194 tocopherol has an important antioxidant activity and is well absorbed by rainbow trout 195 when included on their diets (Timm-Heinrich et al. 2013, Valente et al. 2015). In spite 196 of $\alpha$-tocopherol was not determined on barley, the inclusion of $8 \%$ of barley on rainbow 197 trout diets improved fillet $\alpha$-tocopherol content, and probably enhanced the antioxidant 198 properties of fillets of fish fed with $80 \mathrm{~B}$ diets. Several studies have reported that some 199 vegetable ingredients contain some endogenous antioxidants, which are present in small 200 amounts and can enhance tocopherol antioxidant activity and this might explain the 201 stability of fish fed with 80B diets (Lauritzsen et al. 1999, Thiyam et al. 2006).

\subsection{Oxidative parameters}

\section{3.3.1. Peroxide value (PV) and conjugated hydroperoxides (dienes and trienes)}

204 No differences were observed regardless of the diet on the peroxide value (PV) (Table 205 6). However, when conjugated hydroperoxides (dienes and trienes) were evaluated, it 206 was observed that barley concentration only showed a significant effect $(\mathrm{P}<0.05)$ on 207 trienes (Table 3). The highest value of trienes was observed in control fillets (7.61 208 mmol of hydroperoxides $\mathrm{kg} \mathrm{lipid}^{-1}$ ) and the lowest value in fish fillets at the highest 209 barley concentration (319B) (2.66 mmol of hydroperoxides $\mathrm{Kg} \mathrm{lipid}^{-1}$ ).

210 These results suggested that barley had a positive effect on the control of oxidative 211 process, since oxidative markers were lower in fillets came from fish fed with barley. 212 This could be related to the higher antioxidant activity of fish fed at higher barley 213 concentration and with the lower TBARS values as shown in Pinedo-Gil et al. 2017.

\section{3.4. Antioxidant markers}




\section{$215 \quad 3.4 .1$. Total flavonoid content (TFC) and total phenolic content (TP)}

216 Barley TFC values were of $0.02 \mu \mathrm{g} \mathrm{QE} \mathrm{g}^{-1}$ (Figure 2). Differences in barley flavonoid 217 content may be influenced by genotype, agronomic practices, climatic conditions, 218 maturity at harvest, postharvest and handling and storage conditions (Erdman et al. 219 2007). Total flavonoid content was determined in the different experimental diets it 220 was observed that the substitution of wheat for barley significantly decreased the TFC 221 (Figure 2). Flavonoid content in diets comes from other compounds different from 222 barley.

223 Phenolic acids are present in cereal grains and their content in cereals is usually lower 224 than $1 \%$ of dry matter (Abidi et al. 2015). It has been reported that barley contains more 225 total phenols than wheat (Ragaee et al. 2006, Fogarasi et al. 2015). The value obtained 226 in the study was $1.17 \mathrm{mg}$ of GAE $\mathrm{g}^{-1}$ (Figure 3 ). This result was in accordance with the 227 values obtained by Zhao et al. (2006), who reported that the values of TP varied from 2281.03 to $1.87 \mathrm{mg}$ of GAE $\mathrm{g}^{-1}$. However, TP can vary significantly among barley varieties 229 (Abidi et al. 2015). Surprisingly, it was not expected that diets containing higher barley 230 concentration showed significantly lower TP than control or diets with $4 \%$ and $8 \%$ of 231 barley (Figure 3), since, as it was said before barley contains more total phenols than 232 wheat. The reason of this result could be that phenolic compounds are heat labile 233 (Sharma \& Gujral 2011) and less resistant to the heat that can alter their nature (Sharma 234 et al. 2012). The reduction in TP may be due to the decomposition of phenolic 235 compounds due to the high extrusion temperature during the feed elaboration process.

236 According to these results when TP was determined on fish fillets, TP was higher in 237 fillets of fish fed without barley than those fed with barley, regardless the concentration 238 used (Table 5). 


\section{3.4.2. Individual phenolic compounds}

240 Individual phenolic compounds were determined in barley and experimental diets.

241 HPLC barley profile appears in Figure 4, and the contents of individual phenolic 242 compounds are summarized in Table 4. Eleven phenolic compounds were identified and 243 quantified in barley and the experimental diets. The results showed that maleic acid 244 (14.76 $\left.\mu \mathrm{g} \mathrm{mL}^{-1}\right)$ was the most abundant phenolic compound in barley, followed by 4245 hydroxybenzoic $(5.34 \mu \mathrm{g} \mathrm{mL}-1), 3$-coumaric acid $\left(2.87 \mu \mathrm{g} \mathrm{mL} L^{-1}\right)$, caffeic acid $(2.58 \mu \mathrm{g}$ $\left.246 \mathrm{~mL}^{-1}\right)$, vanillic acid $\left(1.72 \mu \mathrm{g} \mathrm{mL}^{-1}\right)$, gallic acid $\left(1.45 \mu \mathrm{g} \mathrm{mL}^{-1}\right)$, ferulic acid $\left(1.43 \mu \mathrm{g} \mathrm{mL}^{-}\right.$ $\left.24{ }^{1}\right)$, 4-coumaric acid $\left(1.40 \mu \mathrm{g} \mathrm{mL}^{-1}\right)$, syringic acid $\left(0.97 \mu \mathrm{g} \mathrm{mL}^{-1}\right)$, chlorogenic acid $(0.65$ $\left.248 \mu \mathrm{g} \mathrm{mL} L^{-1}\right)$ and transcinnamic acid $\left(0.50 \mu \mathrm{g} \mathrm{mL}^{-1}\right)$. These results were not in agreement to 249 results reported by Naczk \& Shahidi (2006) where ferulic acid and hydroxybenzoic acid 250 were the main phenolics. Probably differences can be associated to the variety of barley.

251 In this study naked barley was used and the lack of cover or peel can be the responsible 252 on the differences on the profile.

253 When the different phenolic compounds were determined in the experimental diets 254 results showed that the inclusion of barley increased 4-coumaric acid content and 255 decreased maleic acid content. This study showed no differences on the rest of the 256 phenolic compounds.

\section{3.4.3. Fillets antioxidant activity}

258 The antioxidant activity of fish fillets from fish fed with the different experimental diets 259 was evaluated through total phenol content (TP) and ORAC activity. Table 5 shows that 260 TP was higher in fillets of fish fed without barley than those fed with barley, regardless 261 the concentration used. However, antioxidant capacity measured using ORAC method, 262 showed that fillets from fish fed $8 \%$ barley concentration had the highest antioxidant 
263 activity. Probably, the absence of correlation between ORAC and TP could was due to

264 the presence of non-phenolics compounds with high antioxidant activity. It is important

265 to remember that barley is rich in $\beta$-glucans.

\section{CONCLUSION}

267 Results indicated that the inclusion of barley had an inhibitory effect on fish fillets lipid 268 oxidation probably associated with certain compounds present on barley, which could 269 act by scavenging and reducing lipid oxidation. Concentrations of $8 \%$ barley enhance 270 antioxidant properties, improving $\alpha$-tocopherol content and ORAC values in fish fillets.

271 However, concentrations higher than $8 \%$ produced a negative effect on fish fillets. It 272 can be observed that these effects may be due to the presence of certain bioactive 273 components in barley and not related to the fish growth. More studies should be carried 274 out to investigate which components in barley are the responsible to inhibit lipid 275 oxidation and improve antioxidant properties until a concentration of $8 \%$ of barley. And 276 the reason why higher barley concentrations showed a negative effect on the fish 277 population.

\section{ACKNOWLEDGEMENT}

279 This work was carried out with fundings from INIA grant number 21 (call 2012, BOE280 2012-13337).

\section{REFERENCES}

282 Abidi, I., Mansouri, S., Radhouane, L., Ksouri, R., Mouldi, E.F., and Bouzid S. 2015. 283 Phenolic, Flavonoid and Tannin contents of Tunisian Barley Landraces. Int J Agric 284 Innov Res. 3 (5): 1417-1423. 
286 Alparslan, Y., Baygar, T., Baygar, T., Hasanhocaoglu, H., and Metin C. 2014. Effects of 287 gelatin-based edible films enriched with laurel essential oil on the quality of rainbow 288 trout (Oncorhynchus mykiss) fillets during refrigerated storage. Food Technol Biotech. $28952(3): 325-333$.

290

291 AOCS. 1992. Official method Ce 8-89. Determination of tocopherols and tocotrienols 292 in vegetable oil and fat by HPLC. Champaign, IL: AOCS.

293

294 Blight, E.G., and Dyer, W.J. 1959. A rapid method of total lipid extraction and 295 purification. Can J Biochem Phys. 37 (8): 911-917.

296

297 Bonoli, M., Marconi, E., and Caboni, M. F. 2004. Free and bound phenolic compounds 298 in barley (Hordeum vulgare L.) flours. Evaluation of the extraction capability of 299 different solvent mixtures and pressurized liquid methods by micellar electrokintic 300 chromatography and spectrophotometry. J Chromatogr A. 1057: 1-12.

301

302 Drew, M.D., Ogunkoya, A.E., Janz, D.M., and Van Kessel, A.G. 2007. Dietary 303 influence of replacing fish meal and oil with canola protein concentrate and vegetable 304 oils on growth performance, fatty acid composition and organochlorine residues in 305 rainbow trout (Oncorhynchus mykiss). Aquaculture. 267: 260-268. 
306

307 Erbay, E.A., Dağtekin, B.B., Türe, M., Yeşilsu, A.F., and Torres-Giner, S. 2017.

308 Quality improvement of rainbow trout fillets by whey protein isolate coatings

309 containing electrospun poly( $\varepsilon$-caprolactone) nanofibers with Urtica dioica L. extract

310 during storage. LWT-Food Sci Technol. 78: 340-351.

311

312 Erdman, J.W., Balentine, J.D., Arab, L. Beecher, G., Dwyer, J.T., Folts, J., Harnly, J.,

313 Hollman, P., Keen, C.L., Mazza, G., Messina, M., Scalbert, A., Vita, J., Williamson, G., 314 and Burrowes, J. 2007. Flavonoids and Heart Health. J Nutr 137: 718-737.

316 FAO. 2013. Aquaculture production: quantities 1950-2011. FISHFTAT Plus - universal 317 software for fishery statistical time series [online]. Food and Agriculture Organization 318 of the united Nations (2010), Fisheries and Aquaculture Information and Statistics 319 Service, Rome, Italy.

320

321 Fogarasi, A.L., Kun, S., Tankó, G., Stefanovits-Bányai, E., and Hegyesné-Vecseri, B. 322 2015. A comparative assessment of antioxidant properties, total phenolic content of 323 eikorn, wheat, barley and their malts. Food Chem. 167: 1-6.

325 García-Romero, J., Ginés, R., Izquierdo, M., and Robaina, L. 2014. Marine and 
326 freshwater crab meals in diets for red porgy (Pagrus pagrus): Effect on fillet fatty acid 327 profile and flesh quality parameters. Aquaculture. 420-421: 231-239.

329 International IDF Standards. 1991. Section 74A:1991. International Dairy Federation. 330 IDF-square Vergot 41, Brussels, Belgium.

332 Lauritzsen, K., Martinsen, G., and Olsen, R.L. 1999. Copper induced lipid oxidation 333 during salting of cod (Gadus morhua). J Food Lipids. 299-315.

334

335 Lin, J.Y., and Tang, C.Y. 2007. Determination of total phenolic and flavonoid contents 336 in selected fruirs and vegetables, as well as their stimulatory effects on mouse 337 splenocyte proliferation. Food Chem. 101: 140-147.

339 Naczk, M., and Shahidi, F. 2006. Phenolics in cereals, fruits and vegetables: occurrence, 340 extraction and analysis; review. J Pharm Biomed Anal. 41: 1523-1542.

342 Ou, B., Hampsch-Woodill, M., and Prior R.L. 2001. Development and validation of an 343 improved oxygen radical absorbance capacity assay using fluorescein as the fluorescent 344 probe. J Agric Food Chem. 49: 4619-4926. 
346 Ozden, O. 2005. Changes in amino acid and fatty acid composition during shelf-life of

347 marinated fish. J Sci Food Agric. 85: 2015-2020.

348

349 Pereira de Abreu, D.A., Paseiro Losada, P., Maroto, J., and Cruz, J.M. 2010. Evaluation 350 of the effectiveness of a new active packaging film containing natural antioxidants 351 (from barley husks) that retard lipid damage in frozen Atlantic salmon (Salmo salar L.). 352 Food Res Int. 43: 1277-128.

354 Pinedo-Gil, J., Tomás-Vidal, A., Larrrán-García, A.M., Tomás-Almenar, C., Jover355 Cerdá, M., Sanz-Calvo, M., and Martín-Diana, A.D. 2017. Enhancement of quality of 356 rainbow trout (Oncorhynchus mykiss) flesh incorporating barley on diet without 357 negative effect on rearing parameters. Aquacult Int. 25 (3): 1005-1023. DOI: $358 \quad 10.1007 / \mathrm{s} 10499-016-0091-0$.

360 Pratoomyot, J., Bendiksen, E.Å., Bell, J.G., and Tocher, D.R. 2010. Effects of 361 increasing replacement of dietary fishmeal with plant protein sources on growth 362 performance and body lipid composition of Atlantic salmon (Salmo salar L.). 363 Aquaculture. 305: 124-132.

365 Ragaee, S., Abdel-Aal, E.M., and Noaman, M. 2006. Antioxidant activity and nutrient 366 composition of selected cereals for food use. Food Chem. 98: 32-38. 
368 Razaei, M., and Hosseini, S.F. 2008. Quality assessment of farmed rainbow trout 369 (Oncorhynchus mykiss) during chilled storage. J Food Sci. 73 (6): H93-H96.

370

371 Sandhu, K.S., and Punia, S. 2017. Enhancement of bioactive compounds in barley

372 cultivars by solid substrate fermentation. Food Measure. DOI: 10.1007/s11694-017$3739513-6$.

374

375 Schieber, A., Keller, P., and Carle, R. 2001. Determination of phenolic acids and 376 flavonoids of apple and pear by high-performance liquid chromatography. J Chromatogr 377 A. $910: 265-273$.

378

379 Sealey, W.M., Barrows, F.T., Hang, A., Johansen, K.A., Overtuf, K., LaPatra, S.E., and 380 Hardy, R.W. 2008. Evaluation of the ability of barley genotypes containing different 381 amounts of $\beta$-glucans to alter growth and disease resistance of rainbow trout 382 Oncorhynchus mykiss. Anim Feed Sci Technol. 141: 115-128.

384 Shadman, S., Hosseini, S.E., Langroudi, H.E., and Shabani, S. 2017. Evaluation of the 385 effect of sunflower oil-based nanoemulsion with Zataria multiflora Boiss. essential oil 386 on the physicochemical properties of rainbow trout (Oncorhynchus mykiss) fillets 
387 during cold storage. LWT-Food Sci Technol. 79: 511-517.

388

389 Sharma, P., and Gujral, H.S. 2011. Effect of sand roasting and microwave cooking on 390 antioxidant activity of barley. Food Res Int. 44: 235-240.

391

392 Sharma, P., Gujral, H.S., and Singh, B. 2012. Antioxidant activity of barley as affected 393 by extrusion cooking. Food Chem. 131: 1406-1413.

394

395 Slinkard, K., and Singleton, V.L. 1977. Total phenol analyses: automation and 396 comparison with manual methods. Am J Enology Vitic. 28: 49-55.

397

398 Thiyam, U., Stöckmann, H., and Schwarz, K. 2006. Antioxidant activity of rapeseed 399 phenolics and their interactions with tocopherols during lipid oxidation. J Am Oil 400 Chem'Soc. 83: 523-528.

401

402 Timm-Heinrich, M., Eymard, S., Baron, C.P., Nielsen, H.H., and Jacobsen, C. 2013.

403 Oxidative changes during ice storage of rainbow trout (Oncorhynchus mykiss) fed 404 different ration of marine and vegetable feed ingredients. Food Chem. 136: 1220-1230. 
406 Tocher, D.R., Bell, J.G., MacGlaughin, P., McGhee, F., and Dick, J.R. 2001. 407 Hepatocyte fatty acid desaturation and polyunsaturated fatty acid composition of liver in 408 salmonids: effects of dietary vegetable oil. Comp Biochem Physiol. 130B: 257-270.

409

410 Turchini, G.M., Torstensen, B.E., and Wing-Keong, N. 2009. Fish oil replacement in 411 finfish nutrition. A review. Aquaculture. 1: 10-57.

413 Undeland, I., Stading, M., and Lingnert, H. 1998. Influence of skinning on lipid 414 oxidation in different horizontal layers of herring (Clupea harengus) during frozen 415 storage. J Sci Food Agric. 78: 441-451.

416

417 Valente, L.M.P., Rema, P., Ferraro, V., Pintado, M., Sousa-Pinto, I., Cunha, L.M., 418 Oliveira, M.B., and Araújo, M. 2015. Iodine enrichment of rainbow trout flesh by 419 dietary supplementation with the red seaweed Gracilaria vermiculophylla. Aquaculture. $420 \quad 446: 132-139$.

422 Volpe, M.G., Siano, F., Paolucci, M., Sacco, A., Sorrentino, A., Malinconico, M., and 423 Verricchio, E. 2015. Active edible coating effectiveness in shelf-life enhancement of 424 trout (Oncorhynchus mykiss) fillets. LWT-Food Sci Technol. 60: 615-622. 
426 Yildiz, M., Kose, I., Issa, G., Kahraman, T., Guven, E., Baltaci, M.A., and Yuruten, K. 427 2016. Cold storage effects on flesh quality of rainbow trout Oncorhynchus mykiss 428 (Walbaum, 1792) fed diets containing different vegetable oils. J Appl Ichthyol. 32: 569429576.

430

431 Zhao, H., Dong, J., Lu, J., Chen, J., Li, Y., Shan, L., Lin, Y., Fan, W., and Gu, G. 2006. 432 Effects of extraction solvent mixtures on antioxidant activity evaluation and their 433 extraction capacity and selectivity for free phenolic compounds in barley (Hordeum 434 vulgare L.). J Agric Food Chem. 54: 7277-7286. 
1 Table 1. Fatty acid profiles (FA) of barley and experimental diets.

\begin{tabular}{lcccccc}
\hline & \multirow{2}{*}{ Barley } & \multicolumn{5}{c}{ DIETS $^{1}$} \\
\cline { 3 - 7 } & & $\mathbf{0 B}$ & $\mathbf{4 0 B}$ & $\mathbf{8 0 B}$ & $\mathbf{1 6 0 B}$ & 319B \\
\hline SFA & & & & & & \\
C14:0 & 0.00 & 0.205 & 0.125 & 0.200 & 0.195 & 0.200 \\
C16:0 & 0.36 & 2.22 & 2.28 & 2.29 & 2.30 & 2.38 \\
C18:0 & 0.36 & 3.81 & 2.125 & 0.50 & 0.49 & 0.59 \\
MUFA & & & & & & \\
C16:1 & 0.00 & 0.23 & 0.24 & 0.23 & 0.24 & 0.22 \\
C18:1 (n-9) & 0.00 & 0.00 & 1.89 & 3.57 & 3.57 & 3.30 \\
PUFA & & & & & & \\
C18:2n6 & 0.84 & 5.61 & 5.49 & 5.03 & 5.01 & 3.82 \\
C18:3n3 & 0.03 & 0.42 & 0.42 & 0.39 & 0.39 & 0.3 \\
C20:5n3 (EPA) & 0.00 & 0.27 & 0.27 & 0.11 & 0.21 & 0.09 \\
C22:6n3 (DHA) & 0.02 & 0.46 & 0.44 & 0.40 & 0.38 & 0.27 \\
\hline 12 Experimental diets: 0B (0\% barley); 40B (4\% barley); $80 \mathrm{~B}(8 \%$ barley); $160 \mathrm{~B}(16 \%$ barley); \\
319B (31.92\% barley).
\end{tabular}

$4 \quad$ SFA (saturated fatty acid); MUFA (monounsaturated fatty acid); PUFA (polyunsaturated fatty

5 acid); DHA (docosahexaenoic acid, 22:6 n-3); EPA (Eicosapentaenoic acid, 20:5 n-3).

6 Table 2. Fatty acid profile (FA) of rainbow trout fillets when fish were fed with

$7 \quad$ increasing barley levels (data are expressed as \% of dry matter) $(n=12)$.

\begin{tabular}{|c|c|c|c|c|c|c|c|}
\hline & \multicolumn{5}{|c|}{ DIETS $^{1}$} & \multirow{2}{*}{ SEM } & \multirow{2}{*}{ Sign. } \\
\hline & $\mathbf{0 B}$ & 40B & $80 \mathrm{~B}$ & 160B & 319B & & \\
\hline SFA & 20.24 & 20.74 & 21.27 & 17.29 & 19.94 & 1.47 & N.S. \\
\hline $\mathrm{C} 14: 0$ & $1.57^{\mathrm{ab}}$ & $1.66^{\mathrm{abc}}$ & $1.70^{b c}$ & $1.40^{\mathrm{a}}$ & $1.89^{\mathrm{c}}$ & 0.10 & $* *$ \\
\hline MUFA & 33.22 & 33.95 & 35.52 & 43.49 & 37.70 & 3.58 & N.S. \\
\hline C16:1 & $2.37^{\mathrm{ab}}$ & $2.75^{\mathrm{b}}$ & $2.67^{\mathrm{b}}$ & $2.05^{\mathrm{a}}$ & $3.36^{\mathrm{c}}$ & 0.16 & $* *$ \\
\hline C18:1 (n-9) & 27.27 & 27.61 & 29.08 & 38.05 & 30.40 & 3.86 & N.S. \\
\hline PUFA & 46.54 & 45.31 & 43.21 & 39.22 & 42.36 & 2.56 & N.S. \\
\hline$n-3$ & 14.60 & 13.98 & 13.69 & 12.52 & 12.70 & 0.94 & N.S. \\
\hline$n-6$ & 31.39 & 30.97 & 29.09 & 24.79 & 29.18 & 1.63 & N.S. \\
\hline n-9 & 30.86 & 31.20 & 32.86 & 41.44 & 34.34 & 3.70 & N.S. \\
\hline$n-3 / n-6$ & 0.47 & 0.45 & 0.47 & 0.50 & 0.44 & 0.03 & N.S. \\
\hline ARA & 0.75 & 0.68 & 0.68 & 0.61 & 1.43 & 0.36 & N.S. \\
\hline EPA & 2.07 & 2.02 & 2.06 & 1.99 & 178 & 0.17 & N.S. \\
\hline DHA & 8.88 & 8.28 & 7.95 & 7.25 & 7.37 & 0.60 & N.S. \\
\hline ARA / EPA & 0.37 & 0.33 & 0.33 & 0.32 & 0.85 & 0.22 & N.S. \\
\hline
\end{tabular}


EPA / DHA 0.24 0.24 0.26 0.27 0.24 0.01 N.S.

$9 \quad$ SFA (saturated fatty acids); MUFA (monounsaturated fatty acids); PUFA (polyunsaturated fatty 10 acids); ARA (arachidonic acid, 20:4 n-6); DHA (docosahexaenoic acid, 22:6 n-3); EPA

11 (Eicosapentaenoic acid, 20:5 n-3).

12 Different superscript letters indicate significant differences $(\mathrm{P}<0.05)$ between the experimental 13 diets. ** indicates P-values $<0.0001$.

14 Table 3. Effect of barley on the peroxide value (PV) and conjugated 15 hydroperoxides (dienes and trienes) of rainbow trout fillets of fish fed at different 16 barley concentrations (data are expressed as \% of dry matter) $(n=12)$.

\begin{tabular}{cccccccc}
\hline & \multicolumn{7}{c}{ DIETS $^{1}$} \\
\cline { 2 - 8 } & 0B & 40B & 80B & 160B & 319B & SEM & Sign. \\
\hline PV & 13.26 & 12.87 & 11.83 & 11.77 & 7.62 & 3.40 & N.S. \\
Dienes & 18.65 & 15.70 & 18.00 & 17.46 & 13.71 & 1.35 & N.S. \\
Trienes & $7.61^{\mathrm{b}}$ & $4.02^{\mathrm{a}}$ & $4.46^{\mathrm{a}}$ & $4.18^{\mathrm{a}}$ & $2.66^{\mathrm{a}}$ & 1.07 & $*$ \\
\hline
\end{tabular}
${ }^{1}$ Experimental diets as shown in table 1.

18 Different superscript letters indicate significant differences $(\mathrm{P}<0.05)$ between the experimental 19 diets. * indicates P-values $>0.0001$

20 Table 4. Contents in individual phenolic compounds $\left(\mu \mathrm{g} \mathrm{mL}^{-1}\right)$ in barley and 21 experimental diets.

\begin{tabular}{|c|c|c|c|c|c|c|c|}
\hline & & \multirow{2}{*}{ Barley } & \multicolumn{5}{|c|}{ DIETS } \\
\hline & & & OB & 40B & $80 B$ & 160B & 319B \\
\hline 1 & Gallic acid & 1.45 & 69.97 & 18.65 & 89.28 & 40.78 & 59.06 \\
\hline 2 & Maleic acid & 14.76 & 94.52 & 79.17 & 53.59 & 45.30 & 56.73 \\
\hline 3 & 4-hydroxybenzoic acid & 5.34 & 4.14 & 4.10 & 2.20 & 3.35 & 3.91 \\
\hline 4 & Chlorogenic acid & 0.65 & 0.11 & 1.61 & 5.03 & 11.78 & 17.60 \\
\hline 5 & Vanillic acid & 1.72 & 4.30 & 6.52 & 3.53 & 2.01 & 3.60 \\
\hline 6 & Caffeic acid & 2.58 & 4.45 & 2.63 & 4.42 & 2.52 & 2.52 \\
\hline & Syringic acid & 0.97 & 0.23 & 0.89 & 0.41 & 2.65 & 7.68 \\
\hline & 4-coumaric acid & 1.40 & 0.06 & 0.11 & 0.10 & 0.44 & 0.70 \\
\hline
\end{tabular}


1

\begin{tabular}{rlcccccc}
$\mathbf{9}$ & Ferulic acid & 1.43 & 1.02 & 0.68 & 0.65 & 0.07 & 0.01 \\
$\mathbf{1 0}$ & 3-coumaric acid & 2.87 & 3.66 & 6.89 & 1.95 & 1.95 & 1.95 \\
$\mathbf{1 1}$ & Transcinamic acid & 0.50 & 5.78 & 8.11 & 1.04 & 11.58 & 12.93 \\
\hline
\end{tabular}

$22 \cdot$ Experimental diets as shown in table 1.

23 Table 5. Effect of barley on antioxidant properties of rainbow trout fillets of fish

24 fed at different barley concentrations (data are expressed as \% of dry matter) $25 \quad(n=12)$.

\begin{tabular}{lccccccc}
\hline & \multicolumn{7}{c}{ DIETS $^{1}$} \\
\cline { 2 - 7 } & 0B & 40B & 80B & 160B & 319B & SEM & Sign. \\
\hline TP $(\boldsymbol{\mu m o l}$ Trolox Eq. $\mathbf{g - 1})$ & 224.39 & 194.20 & 214.91 & 216.54 & 188.63 & 15.45 & N.S. \\
ORAC $\left(\boldsymbol{\mu m o l ~ T r o l o x ~ E q . ~} \mathbf{g}^{-1}\right)$ & 18.43 & 18.93 & 20.07 & 16.70 & 17.04 & 1.39 & N.S. \\
\hline
\end{tabular}

$26{ }^{1}$ Experimental diets as shown in table 1.

27 Total phenols (TP), ORAC (oxygen radical absorbance capacity).

28 Different superscript letters indicate significant differences $(\mathrm{P}<0.05)$ between the experimental 29 diets. 


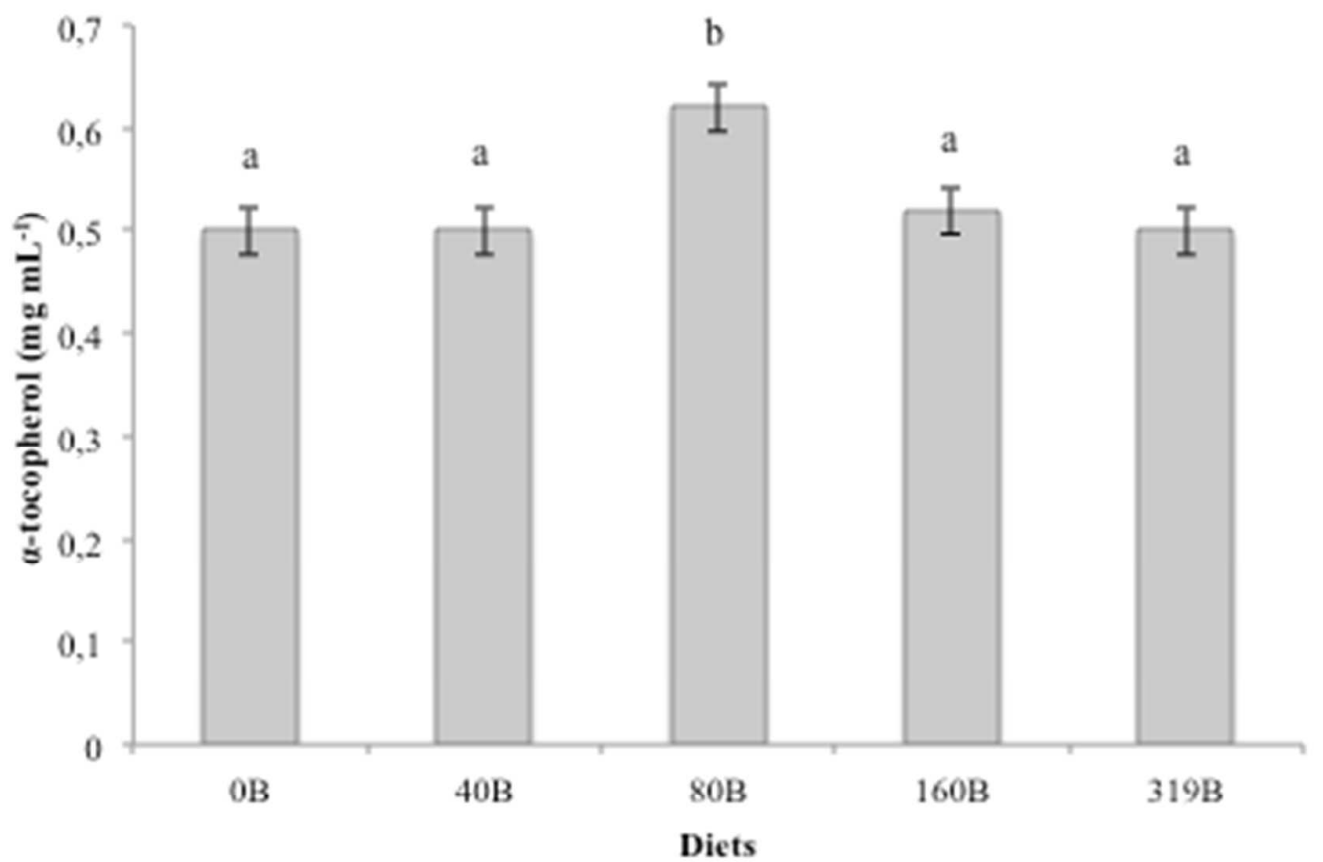

1

2 Figure 1. Fillet alpha-tocopherol content of fish fed different experimental diets $(n=12)$.

3 Different experimental diets: 0B (0\% barley); 40B (4\% barley); 80B (8\% barley); 160B

$4 \quad(16 \%$ barley); 319B (31.92\% barley). Different small letters (a, b) correspond to

5 significant differences $(\mathrm{P}<0.05)$ between different samples.

6

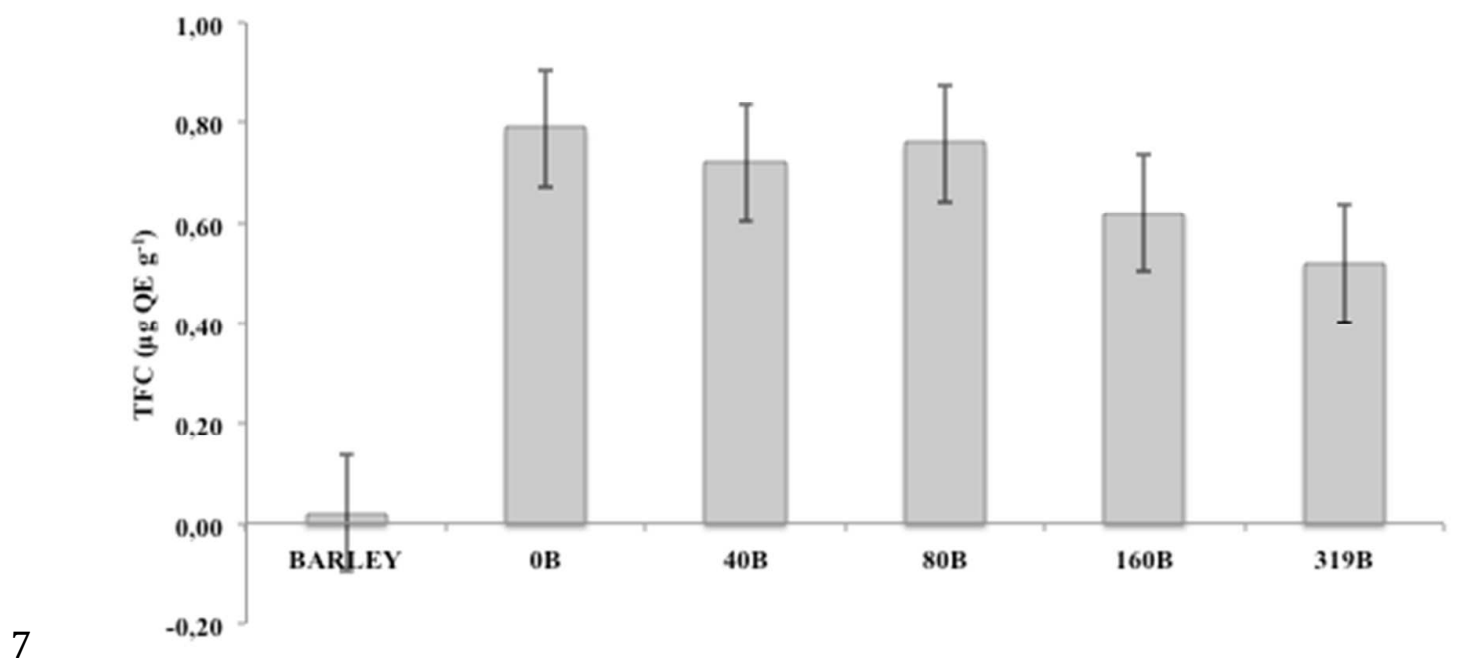




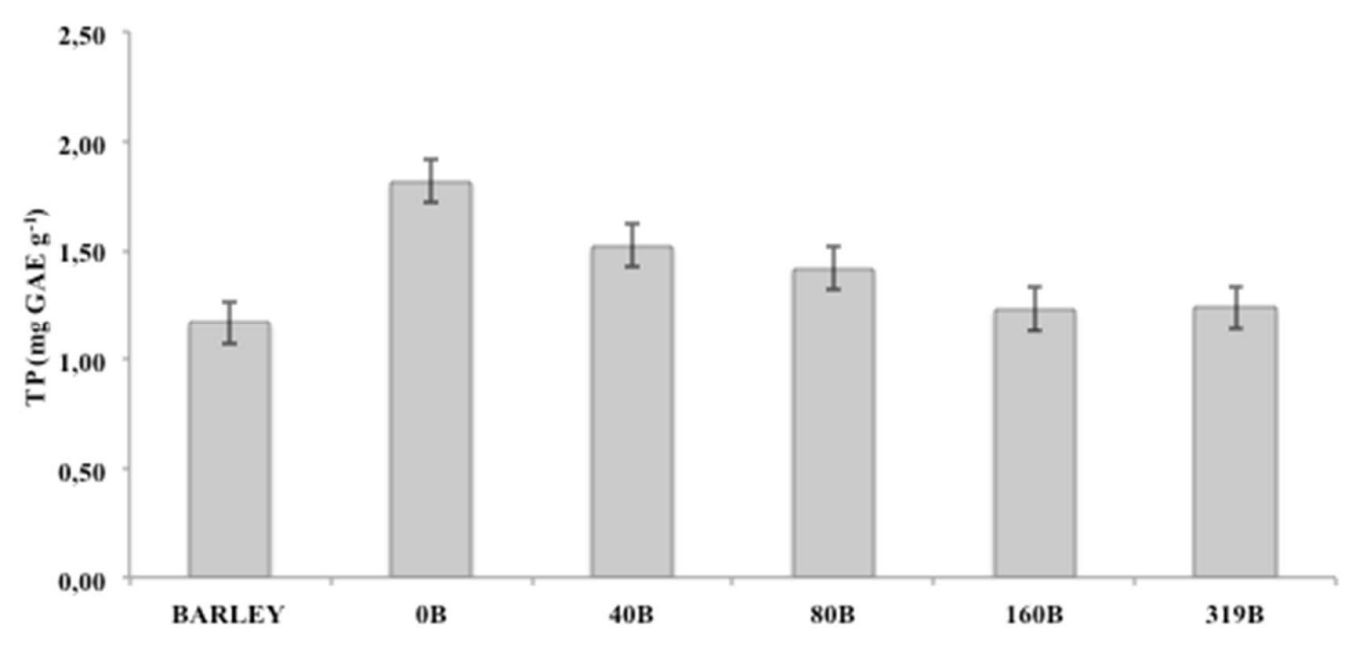

13 Figure 3. Barley and experimental diets total phenolic contents (TP). Different 14 experimental diets: 0B ( $0 \%$ barley); 40B (4\% barley); 80B (8\% barley); $160 \mathrm{~B}$ (16\% 15 barley); 319B (31.92\% barley).

16

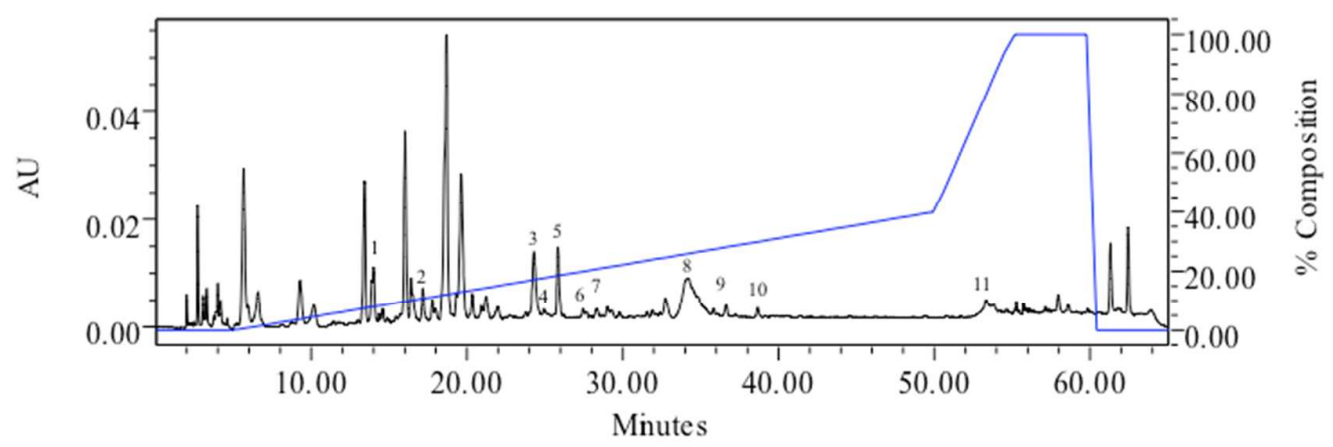

17

18 Figure 4. HPLC chromatogram of phenolic compounds profile in barley extracts. 1.

19 Gallic acid; 2. Maleic acid; 3. 4-hydroxybenzoic acid; 4. Chlorogenic acid; 5. Vanillic 
20 acid; 6. Caffeic acid; 7. Syringic acid; 8. 4-coumaric acid; 9. Ferulic acid; 10. 321 coumaric acid; 11 . Transcinamic acid. 